\title{
The Fertility Transition in Iran: Revolution and Reproduction
}

\author{
by M.J. Abbasi-Shavazi, P. McDonald, and M. Hosseini-Chavoshi \\ New York: Springer, 2009 \\ ISBN 978-90-481-3197-6 \\ US\$139.00, xxiv + 195 pp.
}

\author{
Reviewed by Amir Erfani \\ Department of Sociology \\ Nipissing University (North Bay, ON) \\ amire@nipissingu.ca
}

The Islamic Republic of Iran has experienced perhaps the most rapid and far-reaching fertility decline demographers have ever witnessed. After the 1979 Islamic Revolution, the total fertility rate, which rose slightly to 7.0 children during 1980-84, dropped by more than 5 children to below-replacement-level fertility (1.9 children) in 2006. This is a remarkable fertility transition, as the government policy in Iran never resorted to the types of coercive measures that have been employed elsewhere. This book is the first volume that attempts to explain the rapid fall in fertility after the 1979 revolution.

The most striking feature of the book is its use of a wealth of data, taken from three censuses as well as the 2000 Demographic and Health Survey and two fertility surveys conducted by the authors in 2002 and 2005 among four provinces of Iran. Various demographic methods are applied to estimate fertility levels and to interpret the data. The book is easy to read, and each chapter is written concisely with a clear organization, though it is sadly marred by an undue number of typographical, editorial, and technical errors (for example, see pages 36, 46-47, 56, 97, 100, 104, 108, 111, 128, 130, 154, 156, 165, and 182). Although most of the errors are not serious, the cumulative effect may discourage the reader and weaken confidence in the argument.

The book has ten chapters, including fascinating estimations of fertility levels, analyses, and discussions, which largely had appeared before in journal articles and working papers. To explain the fertility transition in Iran, the authors start with a review of conventional fertility theories, followed by a solid, concise description of socioeconomic and political contexts of changes in the population policies before and after the 1979 Islamic Revolution. They argue that a series of structural and individual-level changes, including the war-induced economic hardship, a rise in women's literacy and age at first marriage, socioeconomic developments of deprived rural areas, and a successful nationwide family planning program, all together contributed to the rapid fertility transition in Iran. In subsequent chapters, they analyze the fertility-inhibiting effects of marriage structure and contraceptive use, and investigate the influence of women's autonomy and changes in family-related behaviours and attitudes across cohorts of women on the fertility decline observed in Iran. 
The trends of fertility rates and the quantum of successive births are subtly illustrated in chapters 3 and 4, according to the single-calendar-year fertility rates and the synthetic parity progression ratios estimated competently for the national and sub-national populations. Chapters 5-7 are devoted to studying the role of marriage and contraceptive use in the rapid fertility decline. Consistent with previous findings (Erfani and McQuillan 2008a), they document an important reduction in marital fertility, particularly among young women, and increasing trends of effective modern contraceptive use over the period of fertility transition in Iran.

While chapter 7 includes competent analyses of contraceptive histories and an efficient use of graphs, representing dynamics of lifetime contraceptive use among different marriage cohorts of women, chapter 6 is poorly set and organized, with many methodological and editorial mistakes. It looks like that chapter was taken from a broader text without enough tailoring and modifications. The results in Table 6.10, for example, are based on binary logistic regressions, while the authors state that they have used "multinomial logistic regression" and the results are based on applying "multiple classification analysis (MCA)" (p. 108). It is also unfortunate that the book did not devote any chapter to the dynamics of abortion and lactational infecundability behaviours, given the available data in provincial surveys. Despite the fact that the authors argue that "in theory, only [proportion ever marrying, contraception and abortion] could have been involved in the massive fall of fertility that has been observed in Iran" (p. 5), it is of great importance to include abortion and postpartum infecundability in the analyses of fertility decline in Iran, as about 8 per cent of the reduction in the fertility is attributed to these two factors, and important provincial variations in abortion and lactational behaviours have been documented, as well (Erfani and McQuillan 2008a, 2008b).

In chapter 8 , the authors examine the association between changes in the family and familial behaviours and attitudes and fertility trends in Iran. They argue that contrary to the Western model, in which the fall in fertility was associated with the emergence of alternative forms of family unions and a rise in divorce, the below-replacement-level fertility in Iran was achieved within marriage by postponing parenthood through the effective use of contraceptives. This is a novel contribution of the book to the literature, which deserves further investigation. In the rest of the chapter, the authors try to establish a causal relationship between "the fertility trend and the transformation of attitudes and values toward family and fertility" (p. 158), and adopt an inapt analytical strategy where they compare cross-sectional data on attitudes to family-related behaviours among three birth cohorts of women. There is no doubt that any fertility transition may be preceded by some attitudinal changes which make couples ready to practice available family planning services. However, the measurement of lifetime transformations across different cohorts of women requires longitudinal data to capture the temporal order of variables. Given the cross-sectional nature of the attitudinal data in the survey, the authors are not able to assess the effect of "the transformation of attitudes" on "the fertility trend." The attitudes of women at different age groups were asked at one point in time. Therefore, it is entirely unacceptable to conclude from the cross-sectional data that "Fertility behaviour and attitudes of women have changed across birth and marriage cohorts over the last two decades" (p. 159). The very similar attitudes reported by women of different marriage cohorts in chapter 8 are simply a reflection of the familial norms and values prevailing among all cohorts of women at the time of interview. 
Despite the image of Iranian society as a strict theocratic state, the country has seen an extraordinary improvement in women's schooling and social status. In chapter 9, the authors develop composite measures of different dimensions of women's autonomy to examine the association between women's autonomy and reproductive behaviours. They conclude that compared to women's education, which was highly associated with ideal number of children and contraceptive use, the association between women's autonomy and fertility measures were relatively weak. Limiting the sample to four provinces and the questionable validity of the indicators measuring female autonomy in Iran may be possible reasons for the weak association between women's autonomy and fertility behaviour.

In chapter 10, the authors critically assess the applicability of the conventional theories of fertility to the fertility transition in Iran. In their concluding remark, they state that "no one theory provides a sufficient explanation of the transition," and that there are "certain necessary conditions for a fertility transition to occur." These include "the achievement of low levels of infant and child mortality," "institutional changes," "diffusion of the idea" pertaining to the advantages of limiting births, and the enhancement of "spousal cooperation" for achieving the desired number of children. They believe that "all of these necessary conditions were met in Iran" (p. 185). There is no question that this conclusion can be valid. Nevertheless, the reviewer would have preferred that the authors backed their claim with more solid empirical bases. For instance, throughout the book great credit was given to the role of "economic aspirations" in the fertility decline in Iran, whereas little direct hard data were provided for this assertion. At the end of the chapter, the authors foresee a continuing fertility decline for Iran over the next decade, given the prevailing socioeconomic and demographic situations and constraints in the country.

Regardless of these reservations, this is the first book in the field describing the astonishing fertility transition of Iran. I strongly recommend The Fertility Transition in Iran: Revolution and Reproduction to researchers, policy makers, and senior undergraduate and graduate students who are interested in population changes in Iran, Muslim countries, and the Middle East. This is a book for those who are interested in knowing about the past, present, and future of fertility in Iran.

\section{References}

Erfani, A. and K. McQuillan. 2008a. Rates of induced abortion in Iran: The roles of contraceptive use and religiosity. Studies in Family Planning 39(2):111-22.

Erfani, A. and K. McQuillan. 2008b. Rapid fertility decline in Iran: Analysis of intermediate variables. Journal of Biosocial Science 40(3):459-78. 